\title{
Void Formation and Plastic Deformation Mechanism of a Cold-Rolled Dual-Phase Steel During Tension
}

\author{
Hamid Ashrafi ${ }^{1} \cdot$ Morteza Shamanian $^{1} \cdot$ Rahmatollah Emadi $^{1} \cdot$ Ehsan Ghassemali ${ }^{2}$ \\ Received: 26 July 2019 / Revised: 26 August 2019 / Published online: 4 December 2019 \\ (C) The Chinese Society for Metals (CSM) and Springer-Verlag GmbH Germany, part of Springer Nature 2019
}

\begin{abstract}
The void formation and plastic deformation micromechanisms of a cold-rolled DP600 steel during tensile loading were studied by scanning electron microscopy (SEM) and electron backscatter diffraction (EBSD). The SEM observations revealed that the main void nucleation mechanism in the DP600 steel is decohesion at the ferrite-martensite interfaces. The voids were mostly observed between the closely spaced martensite islands situated at the boundaries of relatively finer ferrite grains. The EBSD results indicated a strain gradient developed from the ferrite-martensite and ferrite-ferrite interfaces into the interior of ferrite grains during the tensile deformation, which led to a stress concentration at these interfaces. Moreover, it was demonstrated that local misorientation inside the finer ferrite grains surrounded by martensite islands was higher than that for the coarser ferrite grains, which made the former more prone to void initiation.
\end{abstract}

Keywords Dual-phase steel · Void nucleation $\cdot$ Fracture mechanism

\section{Introduction}

Dual-phase (DP) steels are the most widely used types of advanced high strength steels (AHSS) which are currently used in auto body structures like A-pillar, front rail closeout and roof structures [1-3]. This is due to their excellent and unique mechanical properties including continuous yielding, high initial strain hardening rate, low yield ratio, good formability along with their simple processing and relatively low cost $[4,5]$. DP steels have a microstructure consisting of hard martensite islands in a soft ferrite matrix [6]. This microstructure is usually created by intercritical annealing of a cold-rolled steel in the intercritical temperature region followed by subsequent quenching [7, 8]. In recent years, many studies have attempted to enhance the mechanical properties of DP steels through the application of thermomechanical processing, controlling the microstructure prior

Available online at http://link.springer.com/journal/40195

Hamid Ashrafi

hamashrafi@gmail.com

1 Department of Materials Engineering, Isfahan University of Technology, Isfahan 84156-83111, Iran

2 School of Engineering, Jönköping University, Box 1026, 55111 Jönköping, Sweden to intercritical annealing and controlling the holding time in the intercritical region [9-11].

Despite their good mechanical properties, the ductility of DP steels is limited due to the initiation and growth of voids in the microstructure with increasing strain. It is understood that the partitioning of strain into the softer ferrite phase can lead to strain localization and therefore early fracture of DP steel [12]. Ductile fracture model is often used to clarify damage behavior of DP steels. According to this model, ductile fracture in DP steels occurs in three sequential stages: (1) void initiation, (2) void growth and (3) void coalescence [13]. Several mechanisms of void nucleation have been proposed for DP steels. Avramovic-Cingara et al. [14] studied damage mechanisms for a DP600 steel sheet during uniaxial tensile testing. They observed that void nucleation mostly occurred by decohesion at the ferrite-martensite interface. A smaller fraction of voids was created as a result of martensite cracking and fracturing. They suggested that the void nucleation occurs during the whole deformation process with a nearly constant rate, and this rate decreases before fracture. Mazinani and Poole [15] investigated the effect of martensite plasticity on the deformation behavior of a low-carbon DP steel. They showed that for conditions where martensite phase co-deforms with the ferrite matrix, void nucleation is prevented and the macroscopic true fracture stress and strain are significantly improved. Studying the effect of martensite morphology and 
distribution on the damage accumulation in two DP steels, Avramovic-Cingara et al. [16] found that void growth rate is slow in DP steels with more uniform distribution of martensite islands. This slow void growth rate accompanied by a continuous void nucleation during the deformation process resulted in a higher void density before fracture. They reported that martensite cracking starts at local strain of 0.029 and void nucleation by ferrite-martensite interface decohesion at the strain of 0.09. Kadkhodapour et al. [17] carried out an analysis of the microstructure and failure mechanism of a commercial high strength DP800 steel as a function of strain. They observed that the dominant fracture mechanism of DP steels is influenced by parameters such as the chemical composition of steel, the martensite volume fraction, the yield stress ratio of ferrite and martensite and the morphology and distribution of the martensite islands. They concluded that fracture mechanism of DP steels cannot be generalized by formulation.

In the available literature on the DP steel damage, mostly scanning electron microscopy (SEM) observations were utilized to analyze the damage behavior, and the deformed microstructure by means of more advanced analysis tools was lacking. Therefore, the present study aims to more comprehensively investigate the void formation micromechanisms in a cold-rolled DP600 steel by using SEM and electron backscatter diffraction (EBSD)

\section{Experimental}

The material used for this research was a 2-mm-thick sheet of DP600 steel. The chemical composition of the steel is given in Table 1. The steel was processed by intercritical annealing and water quenching.

Tensile specimens were machined according to the dimensions given in Fig. 1, so that the applied tensile stress direction corresponded to the transverse direction (TD) of the sheet. Uniaxial tensile testing was carried out at a cross head speed of $1 \mathrm{~mm} / \mathrm{min}$ using a Hounsfield H50KS machine. Each test was repeated three times to obtain an average value for the tensile properties.

Fractured surfaces of the tested specimens were analyzed by SEM in a Philips XL30 microscope. In order to study void nucleation mechanisms, the fractured specimen was sectioned through the thickness along the midwidth in the longitudinal direction using electrical discharge machining (EDM). The sectioned specimen then was mounted, grounded to 4000-grit finish, polished with $0.3-\mu \mathrm{m}$ alumina suspension and etched with $2 \%$ Nital reagent. The samples were then characterized by SEM to reveal the void nucleation mechanisms during the

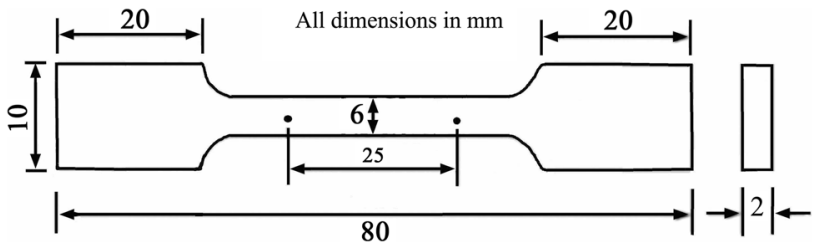

Fig. 1 Geometry and dimensions of the tensile test specimen

tensile testing. The EBSD analysis was also conducted on the un-deformed BM and sectioned specimen on a field emission SEM (JSM7001F) equipped with an EBSD detector combined with the TSL (OIMA) analysis software. The EBSD samples were prepared by conventional metallographic sample preparation followed by polishing with alumina suspension. The accelerating voltage of $15 \mathrm{kV}$ and probe current of $\sim 5 \mathrm{nA}$ was used for this purpose. A step size of $100 \mathrm{~nm}$ was used for all scans, which resulted in $>80 \%$ successful indexing. No artificial cleanup procedure was used for processing of the EBSD data.

\section{Results}

\subsection{Microstructures and Tensile Tests}

Figure 2 shows the image quality (IQ) map of the microstructure of the un-deformed DP600 steel. IQ illustrates the sharpness of Kikuchi patterns at a given point. An elastically distorted lattice will have a faint Kikuchi pattern and a low IQ [18]. Therefore, it is expected that highly distorted regions such as grain boundaries, phase boundaries and martensite phase will have low IQ values. Based on the above arguments, dark areas with low IQ in Fig. 2 were identified as the martensite islands, with polygonal ferrite being the bright areas with high IQ. The volume fraction of martensite was measured to be $\sim 22 \%$ using image analysis. The mean size of ferrite grains and martensite islands was measured to be $5 \pm 0.18 \mu \mathrm{m}$ and $3.6 \pm 0.25 \mu \mathrm{m}$, respectively. The distribution of martensite islands was not completely uniform within the microstructure. As also can be seen in Fig. 2, areas with smaller ferrite grains had a higher fraction of martensite islands.

The representative engineering stress-strain curve of the analyzed DP600 steel is given in Fig. 3. This curve indicates a continuous yielding behavior and a low yieldto-tensile strength ratio, which are typical characteristics of DP steels [19]. Table 2 summarizes the tensile property
Table 1 Chemical composition of DP600 steel used in this study (wt\%)

\begin{tabular}{llllllllllllll}
\hline $\mathrm{C}$ & $\mathrm{Mn}$ & $\mathrm{Si}$ & $\mathrm{S}$ & $\mathrm{P}$ & $\mathrm{Ni}$ & $\mathrm{Mo}$ & $\mathrm{Cu}$ & $\mathrm{V}$ & $\mathrm{Al}$ & $\mathrm{Co}$ & $\mathrm{Nb}$ & $\mathrm{Zr}$ & $\mathrm{Fe}$ \\
\hline 0.18 & 1.25 & 0.2 & 0.01 & 0.011 & 0.015 & 0.019 & 0.019 & 0.02 & 0.073 & 0.045 & 0.023 & 0.011 & Bal. \\
\hline
\end{tabular}




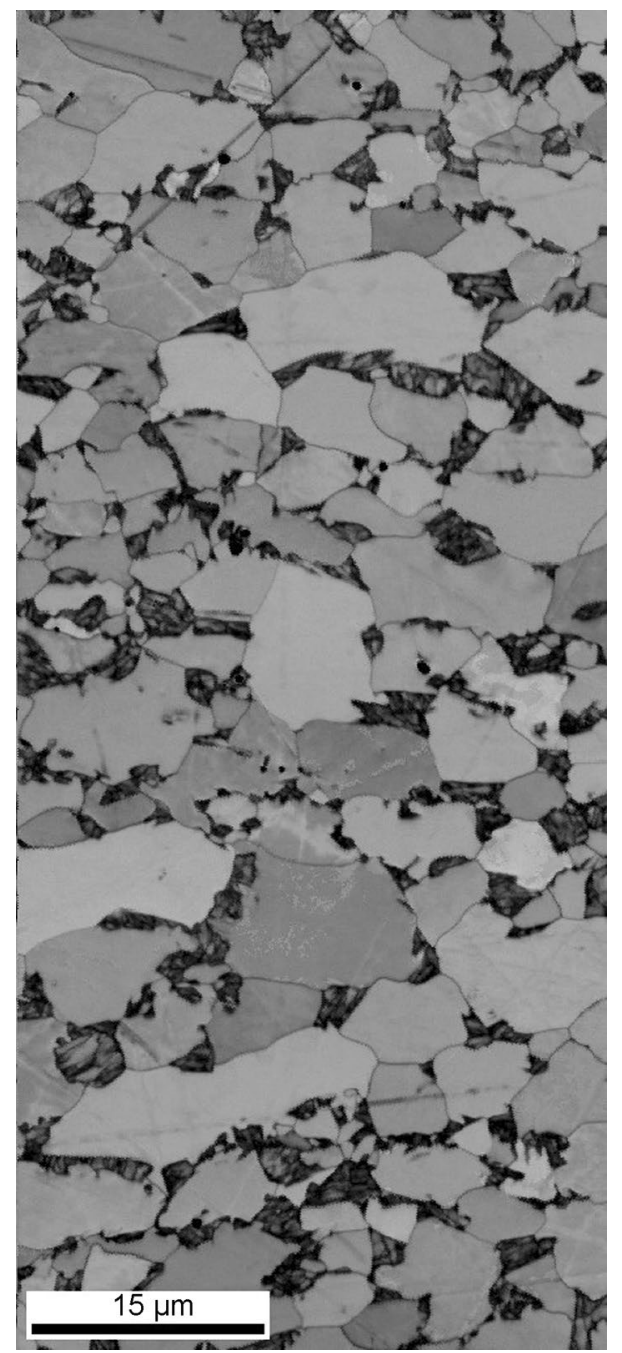

Fig. 2 IQ map of the microstructure of DP600 steel

data. The data are reported in terms of yield strength (YS), ultimate tensile strength (UTS), uniform elongation (UE), total elongation (TE) and yield ratio (YS/UTS).

\subsection{Fracture Surface}

Figure 4 shows the SEM image of the fracture surface of the studied steel. As can be seen, the fracture surface is completely covered with dimples, indicating the ductile fracture behavior. The ductile fracture is specified by equiaxed or elliptical dimple-like depressions in the fracture surface [20]. These dimples formed as a result of the void formation and growth during the plastic deformation of DP steel. The presence of elongated dimples on the fracture surface indicates that a significant amount of plastic deformation occurs before the final fracture of the sample.

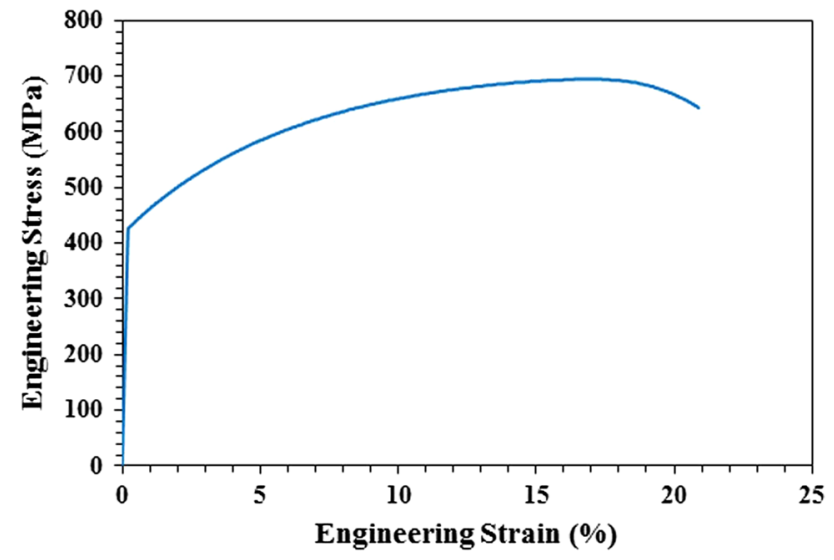

Fig. 3 Engineering stress-strain curve of DP600 steel

Table 2 Tensile properties of DP600 steel

\begin{tabular}{lllll}
\hline YS (MPa) & UTS (MPa) & UE (\%) & TE $(\%)$ & Yield ratio \\
\hline $426 \pm 5$ & $684 \pm 7$ & $17.3 \pm 0.9$ & $21.05 \pm 1$ & 0.62 \\
\hline
\end{tabular}

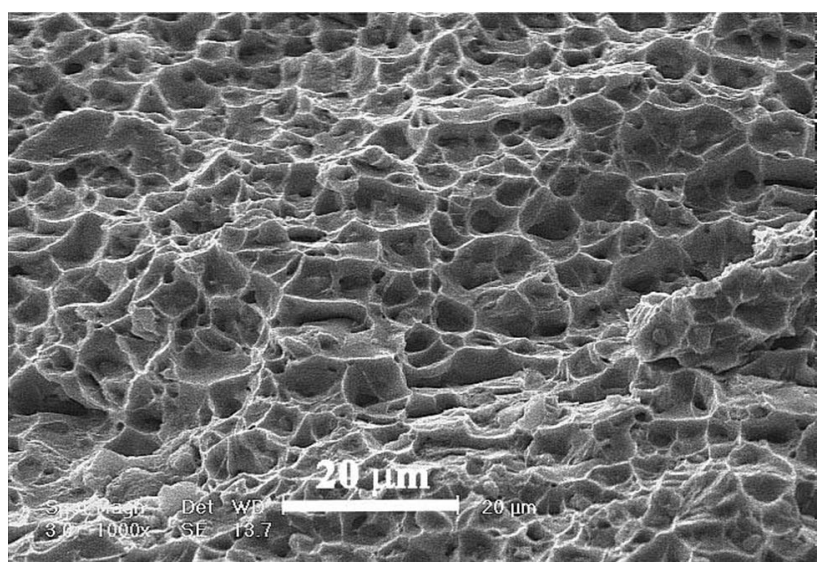

Fig. 4 SEM micrograph of the fracture surface of DP600 steel

\subsection{Void Nucleation Mechanisms}

In order to determine the damage initiation mechanisms, the cross section of tensile-tested specimen was investigated by SEM. In this regard, first the equivalent plastic strain $\left(\varepsilon_{\text {eq }}\right)$ was estimated by the following equation [21]:

$\varepsilon_{\mathrm{eq}}=\frac{2}{\sqrt{3}} \ln \frac{t}{t_{0}}$,

where $t$ is the thickness of specimen at a given point and $t_{0}$ is the initial thickness. The above formula assumes plastic incompatibility and neglects the strain component in the 
normal direction. Figure 5 shows the cross section of the tensile-tested specimen, along with the variation of logarithmic thickness strain as a function of distance from the fracture surface. A typical cup and con fracture is observed in Fig. 5a. Figure 5b shows that the logarithmic thickness strain gradually decreases with distance from the fracture surface. The logarithmic fracture strain was above 0.4 , which is significantly higher than the engineering fracture strain. The microstructural investigations were performed on two locations along the centerline of the cross section: one in the location with the logarithmic thickness strain of 0.15 , and the other in the vicinity of the fracture surface.

SEM micrographs of the area with the logarithmic thickness strain of 0.15 are given in Fig. 6. Both the secondary electron (SE) and back scatter electron (BSE) images are included in this figure. As can be seen, the ferrite grains were elongated in the tensile direction, while the plastic deformation of martensite was negligible. Due to this difference in the plastic deformation behavior, voids were nucleated as a result of the ferrite-martensite interface decohesion [12]. The small size of voids $(<1 \mu \mathrm{m})$ suggested that at the logarithmic thickness strain of 0.15 , the voids were mostly in the nucleation stage. It was also evident from Fig. 6 that the voids were nucleated between the closely spaced martensite islands situated in the boundaries of finer ferrite grains. This is also reported in previous studies [14, 22].

Figure 7 shows the SEM micrographs of the cross section of tensile-tested specimen just behind the fracture surface (equivalent logarithmic strain of 0.4). As can be seen, with increasing the equivalent logarithmic strain to 0.4 in this region, the elongation of ferrite grains in the direction of applied stress increases. A number of the martensite islands are also elongated in the tensile direction. In this area, the voids nucleated at the ferrite-martensite interfaces at lower strain grow in the tensile direction along the ferrite-ferrite grain boundaries and some new voids are also nucleated. Analysis of the location of voids indicates that these voids are mainly nucleated at ferrite-martensite interfaces
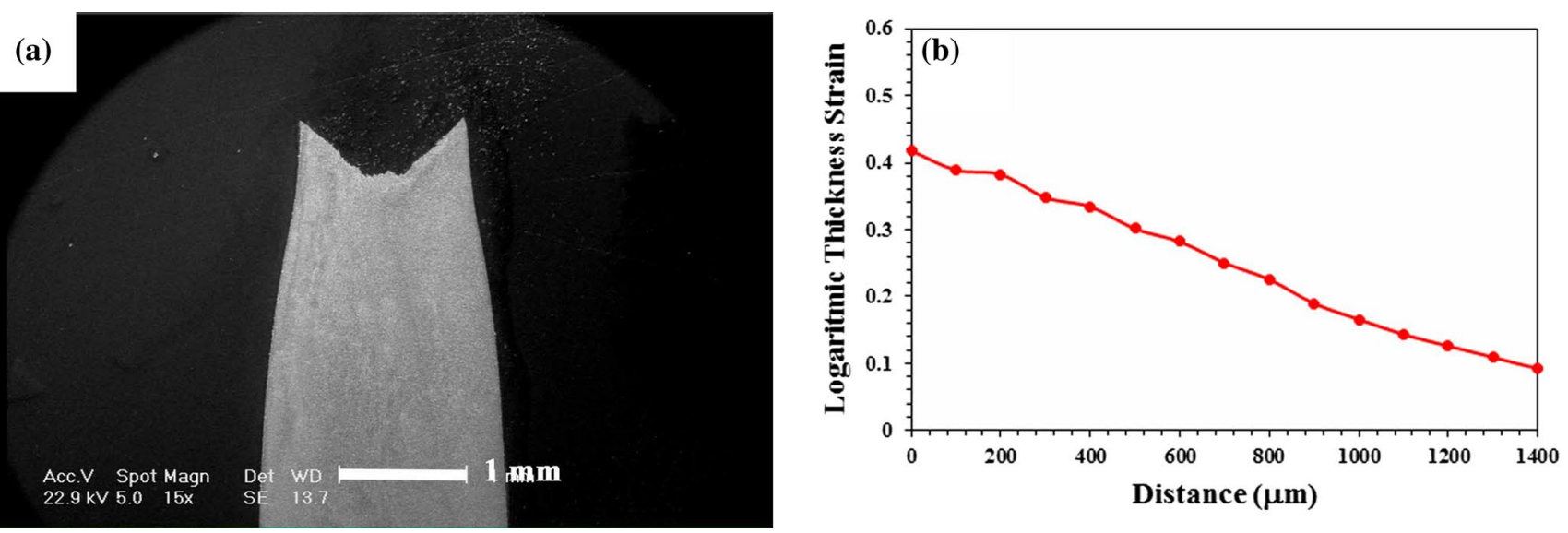

Fig. 5 a SEM micrograph of the cross section of fractured specimen. b Variation of logarithmic thickness strain with distance from the fracture surface
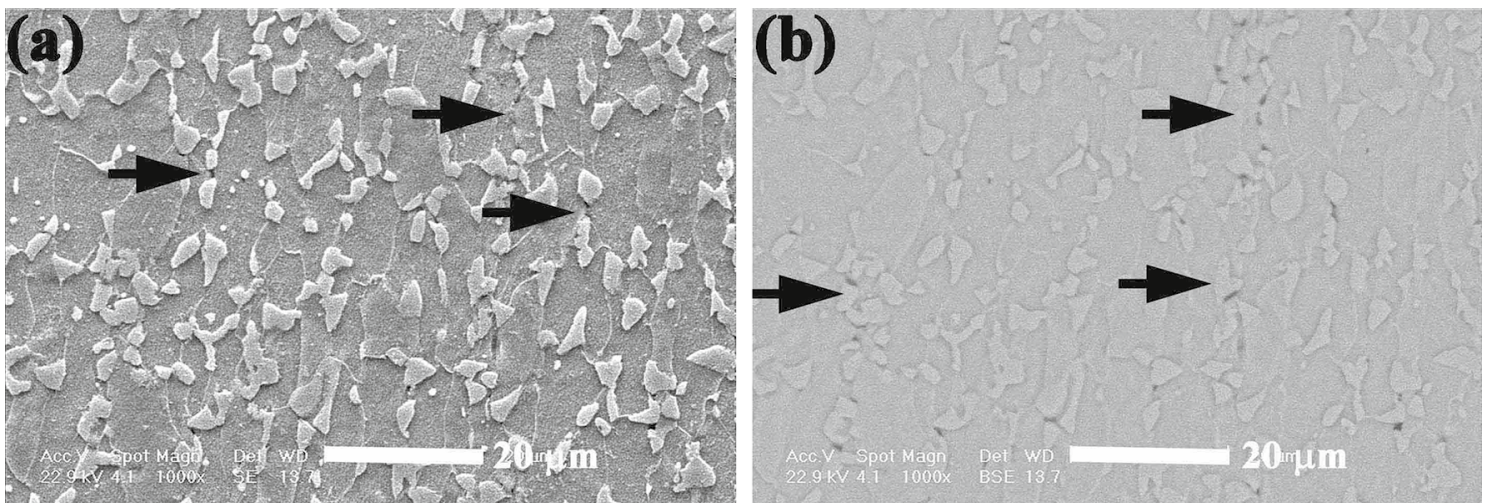

Fig. 6 SEM micrograph of the microstructure of the cross section of the tensile-tested specimen at the position of the equivalent logarithmic strain of 0.15 , a SE image, b BSE image. Arrows show the location of voids 

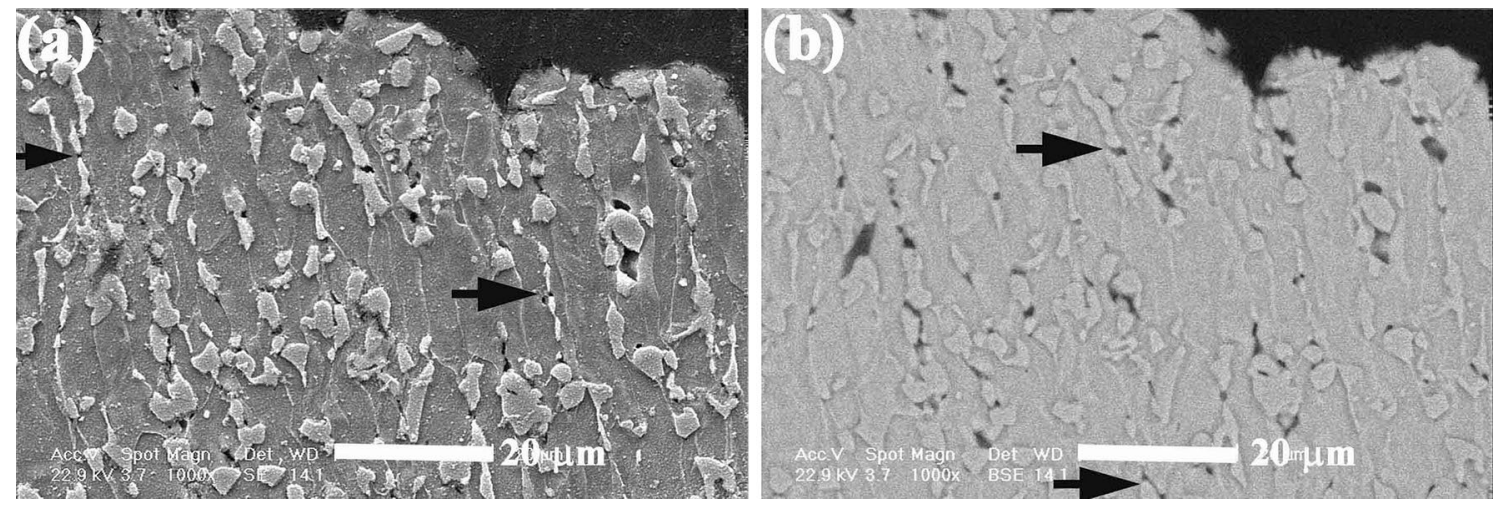

Fig. 7 SEM micrographs of the microstructures of the cross section of the tensile-tested specimen at the position of the equivalent logarithmic strain of 0.4 , a SE image, b BSE image. Arrows show the formation of voids as a result of martensite necking (a), martensite fracturing (b)

perpendicular to the loading direction and between the closely spaced martensite islands. Necking and void formation in the necked region was also observed in some martensite islands (marked with arrows in Fig. 7a). Moreover, it seems that a number of voids are formed due to the cracking and fracturing of martensite phase (marked with arrows in Fig. 7b). The voids were then propagated in the tensile direction along the ferrite grain boundaries. Other voids nucleation mechanisms such as inclusion-matrix interface separation [20] were not observed in the present study.

In order to investigate the micromechanisms involved in the plastic deformation and formation of voids in DP600 steel, Kernel average misorientation (KAM) map of the microstructure was also analyzed. The KAM map represents the quantitative average misorientation of a point with respect to a defined set of nearest neighbors in the same grain and is indicative of local misorientation [23]. In fact, deformed grains have a KAM value larger than $\sim 1^{\circ}$ because of their high dislocation density, while recrystallized grains have KAM value smaller than $1^{\circ}$ [24]. As can be seen in Fig. 8a for the un-deformed DP600 steel, the KAM in the ferrite grains was smaller than $1^{\circ}$, indicating a recrystallized structure. In the deformed samples (Fig. 8b, c), the KAM value of ferrite grains had significantly increased. The distribution of KAM values at different strains is shown in Fig. 9. For the un-deformed sample, a narrow distribution of KAM values, mostly smaller than $1^{\circ}$, was observed. In the deformed samples, a considerable decrease in the peak value was detected, accompanied by a shift of peak KAM value to higher angles and an increase in the fraction of higher misorientation angles. The flattening of the curves indicated that strain was distributed inhomogeneously throughout the ferrite grains. According to the KAM map of deformed samples (Fig. 8b, c), local misorientation around the ferrite-ferrite grain boundaries and ferrite-martensite interfaces exceeded those in the ferrite grain interior. Moreover, local misorientation inside the smaller ferrite grains surrounded by martensite islands was higher than coarse ferrite grains. This can be seen in the grain average misorientation (GAM) maps provided in Fig. 10. The GAM is defined as the average misorientation between each neighboring pair of points inside a grain [23]. It is evident from Fig. 10 that GAM value was higher for smaller ferrite grains than that of large grains.

\section{Discussion}

The microstructure of the current DP600 steel shown in Fig. 2 consisted of fine martensite islands distributed in the boundaries of equiaxed ferrite grains. Ferrite grains in the microstructure were fully recrystallized. When tensile stress applied to the DP steel, due to the difference in the mechanical properties of ferrite and martensite, plastic deformation starts in ferrite while martensite remains in elastic state. Consequently, a strain gradient develops between the interior of ferrite grains and regions near the ferrite-martensite interfaces which results in the increase of the density of the geometrically necessary dislocations (GNDs). This leads to high initial strain hardening rate at low strains due to a rapid multiplication of dislocations and back stresses induced by strain incompatibility [25]. The KAM map of deformed specimen (Fig. 8) showed high misorientation regions around the ferrite-martensite interfaces. During the plastic deformation of ferrite, the stress is transferred to martensite phase. Due to the plastic strain incompatibility between ferrite and martensite, internal stresses are induced at the ferrite-martensite interfaces. If the strength of interface is high enough and the stress concentration overtakes the yield strength of martensite, plastic deformation of martensite can start. On the other hand, if the yield strength of martensite is higher than the strength of interface, decohesion of interface happens and a void forms [26]. By this mechanism, the stored energy at the interface can be released and the strain gradient within the ferrite grain reduced [27]. Raj et al. [28, 

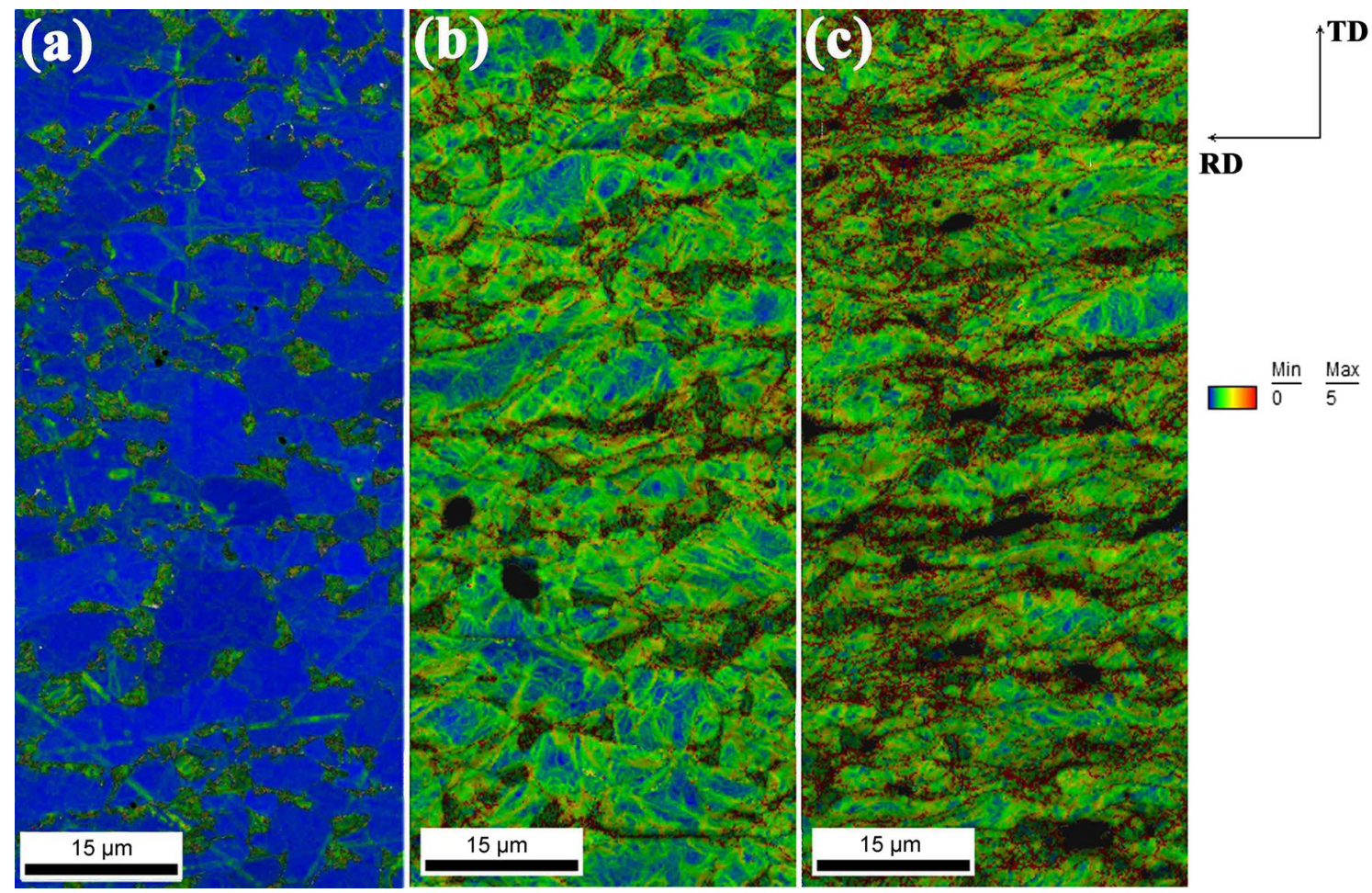

Fig. 8 KAM maps of DP600 steel microstructures at equivalent logarithmic strain of a un-deformed sample, b 0.15 , c 0.4

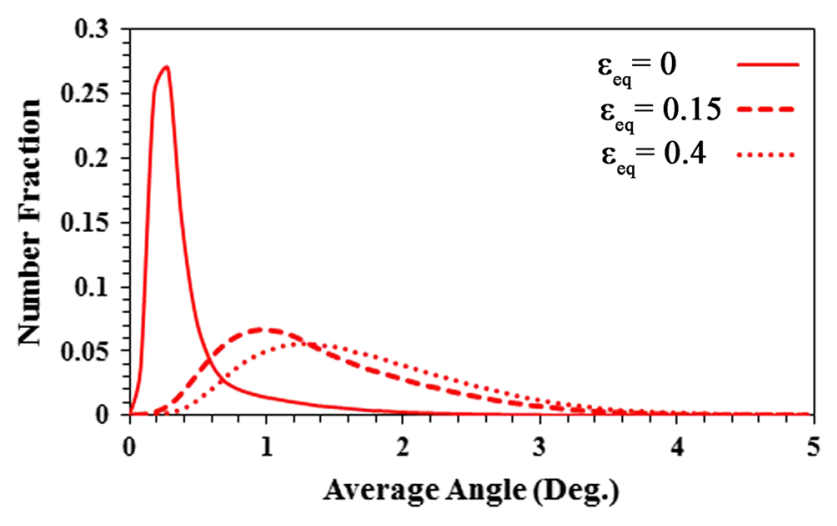

Fig. 9 Distribution of KAM values at different strain levels

29] found that the maximum probability of void formation is at triple junctions connecting a hard particle to the grains of a soft matrix. This is mainly related to lower critical volume of void nucleation in such location in comparison with other locations such as matrix, grain boundaries and phase boundaries. As also indicated in previous studies [17, 30], ferrite-martensite interface decohesion is the most common void nucleation mechanism in DP steels which almost occur in all conditions. Here, this mechanism was also the dominant mechanism of void formation.

Stress concentration and dislocations pileup also can cause martensite cracking (Fig. 7). It is understood that the plasticity of martensite in DP steels depends on parameters such as carbon content, size, morphology and alignment of martensite $[15,31,32]$. Here due to a relatively high carbon concentration of martensite phase ( 0.6), the plasticity of martensite should be small. This is why the plastic deformation of martensite is not significant even at equivalent plastic strain of 0.4 (Fig. 7). Using EBSD analysis, Archi et al. [33] found that initiation and propagation of crack inside martensite in DP steels take place along adhering prior austenite grain boundaries and most of the cracks are almost perpendicular to the tensile direction. They attributed these cracks to the formation of ferrite incursions within a given martensite island along the prior austenite grain boundary. These zones act as stress concentration notch enhancing the fracture of martensite particle. Therefore, martensite cracking is more probable in the martensite islands that transformed from two or more austenite grains and their prior austenite grain boundaries are perpendicular to the tensile direction.

As seen in Fig. 7, a number of martensite islands which have higher plasticity are elongated in the tensile direction. It is understood that the plasticity of martensite was enhanced when the martensite island's morphology is changed from equiaxed to banded [15]. Therefore, banded martensite islands are elongated more easily in the tensile direction in comparison with the equiaxed ones. This plastic deformation of martensite can result in the necking of martensite and formation of void in the necked area (Fig. 7a). Because this mechanism involves 

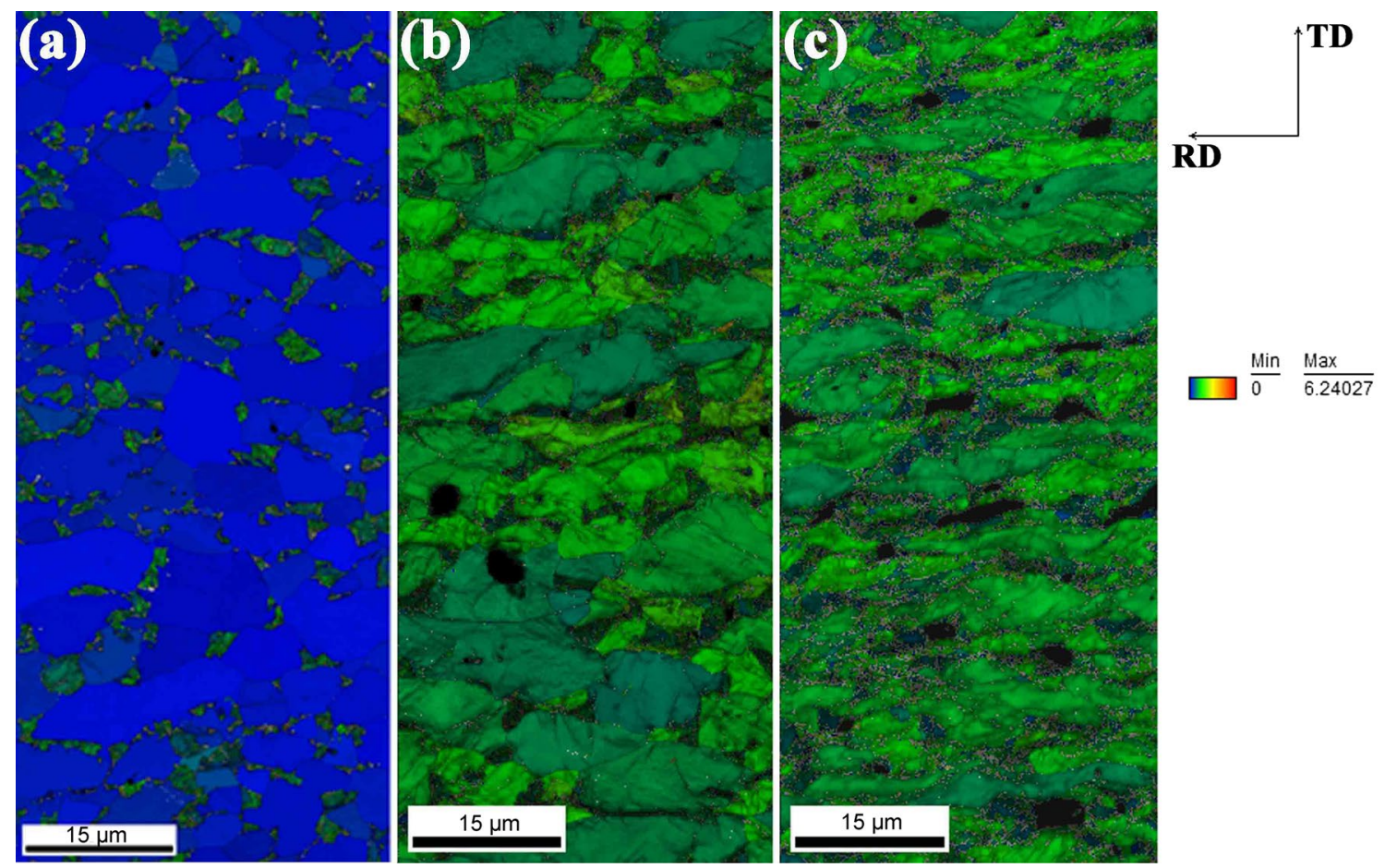

Fig. 10 GAM maps of DP600 steel microstructures at different equivalent plastic strains: a un-deformed sample, b 0.15 , c 0.4

high plastic deformation of martensite, it is only observed in the final deformation stage (Fig. 7).

Ferrite-ferrite grain boundaries also have an influence on the GND density and the number of dislocation sources. In fact, these boundaries are areas with high strain incompatibility, where due to the difference in the orientation of grains on the two sides of the boundary, a strain gradient develops which leads to the formation of GNDs in the vicinity of the ferrite-ferrite grains. The smaller the ferrite grain size, the higher is the fraction of boundaries covered by the martensite islands, and therefore, the higher is the restricting effect of hard martensite islands on the deformation of ferrite grains. In the previous studies on the deformation of DP steels, it was shown that the presence of closely spaced martensite islands on the grain boundaries of ferrite reduces the compatibility of ferrite grains along the grain boundaries during straining [22]. Therefore, it can be concluded that the lower the distance between the martensite islands, the higher is the incompatibility of ferrite grains. Higher incompatibility in this region makes it more prone to void initiation. For this reason, more voids were observed in the regions with closely spaced martensite.

\section{Conclusions}

In the present study, void formation and plastic deformation micromechanisms of a DP600 steel after the uniaxial tensile testing were studied by means of SEM and EBSD. The findings can be summarized as follows:

1. The main void nucleation mechanism in the DP600 steel is ferrite-martensite interface decohesion. Other mechanisms such as martensite necking and martensite cracking are less significant and only observed at high global strains.

2. The voids are mainly nucleated at ferrite-martensite interfaces perpendicular to the loading direction and between the closely spaced martensite islands situated in the boundaries of finer ferrite grains.

3. EBSD results showed that during the plastic deformation, a strain gradient develops from the ferrite-martensite and ferrite-ferrite interfaces into the interior of 
ferrite grains. This strain gradient leads to the stress concentration at these interfaces.

4. KAM and GAM maps revealed that local misorientation inside the smaller ferrite grains surrounded by martensite islands is higher than coarser ferrite grains, which makes these areas more prone to void formation.

\section{References}

[1] T. Sirinakorn, S. Wongwises, V. Uthaisangsuk, Mater. Des. 64, 729 (2014)

[2] M.D. Taylor, K.S. Choi, X. Sun, D.K. Matlock, C.E. Packard, L. Xu, F. Barlat, Mater. Sci. Eng. A 597, 431 (2014)

[3] Y.G. Deng, H.S. Di, J.C. Zhang, Acta Metall. Sin. (Engl. Lett.) 28, $1141(2015)$

[4] H. Ashrafi, M. Shamanian, R. Emadi, M.A. Sarmadi, Steel Res. Int. 89, 1700427 (2018)

[5] Y. Cao, B. Karlsson, J. Ahlström, Mater. Sci. Eng. A 636, 124 (2015)

[6] M. Alibeyki, H. Mirzadeh, M. Najafi, A. Kalhor, J. Mater. Eng. Perform. 26, 2683 (2017)

[7] H. Ashrafi, M. Shamanian, R. Emadi, N. Saeidi, Mater. Sci. Eng. A 680, 197 (2017)

[8] P. Movahed, S. Kolahgar, S.P.H. Marashi, M. Pouranvari, N. Parvin, Mater. Sci. Eng. A 518, 1 (2009)

[9] S. Nikkhah, H. Mirzadeh, M. Zamani, Mater. Chem. Phys. 230, 1 (2019)

[10] M. Nouroozi, H. Mirzadeh, M. Zamani, Mater. Sci. Eng. A 736, 22 (2019)

[11] S. Nikkhah, H. Mirzadeh, M. Zamani, Mater. Sci. Eng., A 736, 22 (2019)

[12] Q. Han, A. Asgari, P.D. Hodgson, N. Stanford, Mater. Sci. Eng. A 611, 90 (2014)
[13] A. Das, S.K. Das, S. Tarafder, Metal. Mater. Trans. A 40, 3138 (2009)

[14] G. Avramovic-Cingara, C.A.R. Saleh, M.K. Jain, D.S. Wilkinson, Metal. Mater. Trans. A 40, 3117 (2009)

[15] M. Mazinani, W.J. Poole, Metal. Mater. Trans. A 38, 328 (2007)

[16] G. Avramovic-Cingara, Y. Ososkov, M.K. Jain, D.S. Wilkinson, Mater. Sci. Eng. A 516, 7 (2009)

[17] J. Kadkhodapour, A. Butz, S.Z. Rad, Acta Mater. 59, 2575 (2011)

[18] J. Wu, P.J. Wray, C.I. Garcia, M. Hua, A.J. Deardo, ISIJ Int. 45, $254(2005)$

[19] M. Maleki, H. Mirzadeh, M. Zamani, Steel Res. Int. 89, 1700412 (2018)

[20] M. Erdogan, J. Mater. Sci. 37, 3623 (2002)

[21] G. Martin, S.K. Yerra, Y. Bréchet, M. Véron, J.D. Mithieux, B. Chéhab, L. Delannay, T. Pardoen, Acta Mater. 60, 4646 (2012)

[22] N. Saeidi, F. Ashrafizadeh, B. Niroumand, F. Barlat, Steel Res. Int. 85, 1386 (2014)

[23] S.I. Wright, M.M. Nowell, D.P. Field, Microsc. Microanal. 17, $316(2011)$

[24] H.P. Lin, D. Chen, J.C. Kuo, Materials 8, 3254 (2015)

[25] M. Calcagnotto, D. Ponge, E. Demir, D. Raabe, Mater. Sci. Eng. A 527, 2738 (2010)

[26] D.L. Steinbrunner, D.K. Matlock, G. Krauss, Metal. Mater. Trans. A 19, 579 (1988)

[27] A.M. Dongare, A.M. Rajendran, B. LaMattina, M.A. Zikry, D.W. Brenner, Phys. Rev. B 80, 1 (2009)

[28] R. Raj, Metal Mater. Trans. A 26, 995 (1978)

[29] R. Raj, M.F. Ashby, Acta Mater. 23, 653 (1975)

[30] C.C. Tasan, M. Diehl, D. Yan, M. Bechtold, F. Roters, L. Schemmann, C. Zheng, N. Peranio, D. Ponge, M. Koyama, K. Tsuzaki, D. Raabe, Annu. Rev. Mater. Res. 45, 391 (2015)

[31] A. Karmakar, M. Ghosh, D. Chakrabarti, Mater. Sci. Eng. A 564, $389(2013)$

[32] J. Zhang, H. Di, Y. Deng, R.D.K. Misra, Mater. Sci. Eng. A 627, $230(2015)$

[33] F. Archie, X. Li, S. Zaefferer, Mater. Sci. Eng. A 701, 302 (2017) 